
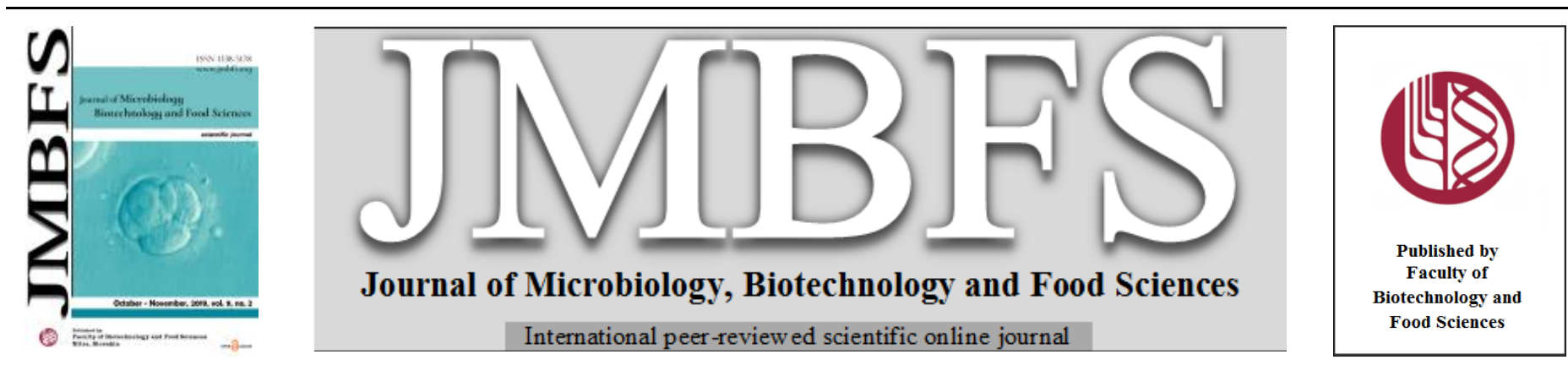

\title{
BIOETHANOL PRODUCTION FROM APPLE POMACE USING CO-CULTURES WITH SACCHAROMYCES CEREVISIAE IN SOLID-STATE FERMENTATION
}

\author{
Dinesh Kumar*, Karan Surya, Rachna Verma \\ Address(es): Dr. Dinesh Kumar, \\ Shoolini University of Biotechnology and Management Sciences, Faculty of Applied Sciences and Biotechnology, Solan 173212, Himachal Pradesh, India.
}

*Corresponding author: dineshkumar@ shooliniuniversity.com

doi: 10.15414/jmbfs.2020.9.4.742-745

\section{ARTICLE INFO}

Received 20. 9. 2018

Revised 2. 9. 2019

Accepted 2. 9. 2019

Published 3. 2. 2020

Regular article

open $\odot$ access

\begin{abstract}
The objective of this study was isolation and screening of apple pomace utilizing microorganisms from soil which can be used as coculture with $S$. cerevisiae for production of bioethanol. In this study, fifteen microorganisms were isolated from soil near the dumping site of apple pomace at HPMC, Parwanoo, H.P. on medium enriched with apple pomace. These isolates were assigned codes APW 1-15 and were screened for their potential to produce cellulase, xylanase and ethanol. The selected isolates were used as co-culture with $S$. cerevisiae for bioethanol production. All the isolates exhibited cellulase and xylanase activities ranging from 228.2 to $502.5 \mathrm{U} / \mathrm{mL} / \mathrm{min}$ and 185.3 to $1010.7 \mathrm{U} / \mathrm{mL} / \mathrm{min}$ respectively, but only three isolates (APW-02, APW-04 and APW-12) produced ethanol. Isolate APW13 exhibited highest cellulase activity $(502.5 \mathrm{U} / \mathrm{mL} / \mathrm{min})$, APW-04 showed highest xylanase activity (1010.7 U/mL/min) and APW-12 produced highest amount of ethanol (36 g/L). Two isolates (APW-12 and APW-13) were selected to co-culture with S. cerevisiae in solid-state fermentation of apple pomace for ethanol production. S. cerevisiae and isolate APW-12 co-culture fermentation resulted in higher ethanol production (49.64 g/L) than $S$. cerevisiae and APW-13 co-culture fermentation (41.7 g/L) while, S. cerevisiae alone produced $37.6 \mathrm{~g} / \mathrm{L}$ ethanol. Isolate APW-12 and APW-13 belonged to genera Actinomyces and Bacillus respectively.
\end{abstract}

Keywords: apple pomace, lignocellulosic waste, ethanol, cellulase, xylanase, Saccharomyces cerevisiae

\section{INTRODUCTION}

Shortage of fossil fuels and increasing global warming has led to worldwide adoption of alternative and renewable energy sources. Energy from biomass has emerged as environment friendly and sustainable solution. This can be attributed to advances made in technology for biofuel production from biomass during recent years. Liquid biofuels like bioethanol, biobutanol and biodiesel are being developed to replace petroleum based fuels in the transportation sector. Biodiesel is produced chemically by conversion of fats and oils present in the biomass. Bioethanol and biobutanol are produced biosynthetically from carbohydrates by microorganisms through fermentation (Wackett, 2008).

Conventionally, alcoholic biofuels are produced from crops like sugarcane, sugarbeet and maize (Scully and Orlygsson, 2014). This increases the pressure on cultivable land being used for growing food crops (Hahn-Hägerdal et al., 2006). To avoid food security issues "lignocellulosic biomass" (agricultural residues, forestry residues, industrial wastes, municipal wastes and energy crops) is being used for production of biofuels because it is inexpensive, abundant, inedible and doesn't exert additional pressure on cultivable land (Jouzani and Taherzadeh, 2015; Choudhary et al., 2016). Lignocellulose is the major component of the plant cell walls. It is generally composed of cellulose (40 $60 \%)$, hemicellulose (20-40\%) and lignin (10-25\%) (Kang et al., 2014). The long chains of glucose units in cellulose are interlinked with hydrogen bonds and compactly packed together to form microfibrils. These microfibrils of crystalline cellulose are embedded in amorphous hemicellulose matrix. Hemicellulose and cellulose are covered by a lignin sheath (Kumar et al., 2009).

Apple pomace is an agro-industrial lignocellulosic waste generated after extraction of apple juice in fruit processing units; comprising of skin, pulp and seed waste of about $25-35 \%$ of fresh apple by weight (Joshi and Attri, 2006). According to Bhushan et al. (2008), fresh apple pomace contains $70-75 \%$ moisture, while $5.5-11.7 \%$ pectin, $7.2-43.6 \%$ cellulose, $4.26-24.4 \%$ hemicellulose and 15.3-23.5\% lignin is present on dry weight basis. Moreover, Pathania et al. (2018) collected apple pomace from the same source as used in the present study (HPMC, Parwanoo, Himachal Pradesh, India) and reported cellulose 36\%, hemicellulose $11 \%$, lignin $19 \%$ and pectin $16.6 \%$ on dry weight basis. Although, apple pomace has high amount residual sugars and polysaccharides, it is generally dumped in landfills. It is prone to microbial growth and spoilage causing environmental pollution (Gama et al., 2015). Initial cost of biofuel production can be reduced by using inexpensive, inedible and waste feedstock like apple pomace and by use of microorganisms which can directly utilize lignocellulosic biomass and efficiently produce biofuel from it (Berezina $\boldsymbol{e t}$ al., 2009). Such microorganisms require a consortium of enzymes including cellulases and xylanases that enable them to depolymerize cellulose and hemicellulose fraction of lignocellulosic biomass.

In the present study, microorganisms that can directly utilize apple pomace as sole nutrient source were screened on the basis of their ability to produce cellulase, xylanase and ethanol. Selected isolates were investigated for their use as co-culture with Saccharomyces cerevisiae for bioethanol production using apple pomace as substrate in solid-state fermentation

\section{MATERIALS AND METHODS}

Raw materials, microorganisms and media

Fresh apple pomace $(70.89 \%$ w/w moisture) was obtained from Himacha Pradesh Horticultural Produce Processing and Marketing Corporation (HPMC), processing plant at Parwanoo, Himachal Pradesh, India. It was dried in hot air dehydrator at $60{ }^{\circ} \mathrm{C}$. Dried apple pomace was ground to fine powder by using a hand operated mill. The powder was stored in air tight containers at a cool and dry place for further use. Saccharomyces cerevisiae MTCC 173 was obtained from Microbial Type Culture Collection and Gene Bank (MTCC), Institute of Microbial Technology, Chandigarh, India. YEPD medium (yeast extract $1 \%$, peptone $2 \%$ and dextrose $2 \%, \mathrm{pH} 6.0$ ), Apple pomace medium (apple pomace powder $2 \%, \mathrm{pH} 7.0$ ) and Nutrient medium (peptone $0.3 \%$, beef extract $0.5 \%$, sodium chloride $0.5 \%, \mathrm{pH} 7.0$ ) were used to cultivate and maintain the microorganisms at $30^{\circ} \mathrm{C}$.

\section{Isolation and characterization of apple pomace utilizing microorganisms}

Soil samples were aseptically collected in $50 \mathrm{~mL}$ plastic containers from dumping site of apple pomace just outside the fruit processing plant of HPMC Parwanoo, Himachal Pradesh, India. The collected soil was used as a source to isolate microorganisms that are capable of utilizing apple pomace as sole nutrient 
source. The soil samples were serially diluted and spread plated on Apple Pomace Agar (APA) prepared by adding apple pomace powder $(2 \%)$ and agar $(1.5 \%)$ to $100 \mathrm{~mL}$ distilled water and $\mathrm{pH}$ was adjusted to 7.0. After incubation at $30{ }^{\circ} \mathrm{C}$ for $72 \mathrm{~h}$, the colonies that appeared were isolated to pure cultures on APA slants. Microorganisms isolated from soil samples were differentiated on the basis of colony morphology and Gram's staining.

\section{Screening of apple pomace utilizing microorganisms}

\section{Cellulase and xylanase production}

All 15 isolates were screened for cellulose and xylan degrading capability by cellulase and xylanase activity assay respectively (Kim et al., 2012). For preparation of crude enzyme, $1 \mathrm{~mm}$ loop full of isolate was transferred to $10 \mathrm{~mL}$ apple pomace broth (2\% apple pomace powder, $\mathrm{pH} \mathrm{7.0)}$ and incubated at $30^{\circ} \mathrm{C}$ for $24 \mathrm{~h}$. $1 \mathrm{~mL}$ of this culture was centrifuged at $8000 \mathrm{~g}$ for $5 \mathrm{~min}$ and the supernatant was transferred to fresh tube without disturbing the pellet and used as a crude enzyme. For cellulase assay, $0.2 \mathrm{~mL}$ of crude enzyme was added to 0.5 $\mathrm{mL}$ of $1 \%(\mathrm{w} / \mathrm{v})$ carboxymethyl cellulose (CMC) solution (prepared in $0.1 \mathrm{M}$ sodium acetate buffer, $\mathrm{pH} 5.0$ ). To this mixture further $0.3 \mathrm{~mL}$ of sodium acetate buffer $(0.1 \mathrm{M}, \mathrm{pH} 5.0)$ was added and incubated at $50{ }^{\circ} \mathrm{C}$ for $10 \mathrm{~min}$. The reaction was terminated by adding $3 \mathrm{~mL}$ di-nitrosalicylic acid (DNS) reagent. Similarly for xylanase assay, $0.2 \mathrm{~mL}$ of crude enzyme was added to $0.5 \mathrm{~mL}$ of $1 \%(\mathrm{w} / \mathrm{v})$ Birchwood xylan solution (prepared in $0.05 \mathrm{M}$ phosphate buffer, $\mathrm{pH} 6.0$ ). To this mixture further $0.3 \mathrm{~mL}$ of phosphate buffer $(0.05 \mathrm{M}, \mathrm{pH} 6.0)$ was added and incubated at $50{ }^{\circ} \mathrm{C}$ for $10 \mathrm{~min}$. The reaction was terminated by adding $3 \mathrm{~mL}$ DNS reagent. The amount of reducing sugars released was estimated by DNS method (Kumar et al., 2010). One unit of enzyme activity is defined as the amount of enzyme required to produce one $\mu \mathrm{mol}$ of reducing sugars as glucose and xylose equivalent per min under the assay conditions respectively for cellulose and xylanase assay.

\section{Ethanol production}

One $\mathrm{mm}$ loop full of each isolate was transferred to $10 \mathrm{~mL}$ apple pomace broth and incubated at $30^{\circ} \mathrm{C}$ for $72 \mathrm{~h}$. After incubation the culture was centrifuged at $8000 \mathrm{~g}$ for $5 \mathrm{~min}$. Supernatant was then transferred to fresh tube without disturbing the pellet and $1 \mathrm{~mL}$ of this supernatant was analyzed for the estimation of ethanol content by potassium dichromate method (Chatanta et al., 2007) at $660 \mathrm{~nm}$

\section{Identification of selected isolates}

Isolates selected after screening were identified on the basis of their morphological and biochemical characteristics. Gram's staining and biochemica tests viz. IMViC, catalase and carbohydrate fermentation tests were performed according to the procedures mentioned by Aneja (2003).

Bioethanol production using selected microorganisms as co-culture with $S$. cerevisiae

\section{Inoculum Preparation}

One mm loop full of one day old $S$. cerevisiae culture growing on YEPD agar plate was added to $10 \mathrm{~mL}$ YEPD broth. After $24 \mathrm{~h}$ of incubation at $30^{\circ} \mathrm{C}, 1 \mathrm{~mL}$ of this growing culture was inoculated to $100 \mathrm{~mL}$ of fresh YEPD broth and incubated at $30{ }^{\circ} \mathrm{C}$ for $48 \mathrm{~h}$. Culture with 2.0 optical density $\left(\mathrm{OD}_{600}\right)$ was used as seed culture. Similarly, inoculum for co-cultures (APW-12 and APW-13) were prepared in Nutrient agar and broth.

\section{Solid-state fermentation}

Selected apple pomace utilizing microorganisms i.e. APW-12 and APW-13 were used as co-culture with $S$. cerevisiae in solid-state fermentation (SSF) for bioethanol production. Dry apple pomace powder $(5 \mathrm{~g}, \mathrm{pH}$ adjusted to 6.0$)$ was remoistened to $70.89 \%(\mathrm{w} / \mathrm{w})$ moisture level, then autoclaved at $121{ }^{\circ} \mathrm{C}$ for 20 min. SSF was performed with this apple pomace powder using $1 \%(\mathrm{v} / \mathrm{w}) S$ cerevisiae and $1 \%(\mathrm{v} / \mathrm{w})$ co-culture inoculums at $30{ }^{\circ} \mathrm{C}$ and incubated for $72 \mathrm{~h}$ After the SSF was over, $10 \mathrm{~mL}$ of distilled water was added to each conical flask. Samples were withdrawn from this fermentation wash and were analyzed further. Ethanol produced in each SSF was estimated by potassium dichromate method (Chatanta et al., 2007).

\section{RESULTS AND DISCUSSION}

\section{Isolation and characterization of apple pomace utilizing microorganisms}

In the present study, soil samples were collected from apple pomace dumping site of HPMC, Parwanoo, India and serially diluted on APA enrichment medium. Fifteen different microbial isolates were obtained and were given codes APW 1 15. These isolates were characterized on the basis of colony morphology and Gram's staining (Table 1).

Singh et al., (2015) in a similar study isolated 50 microorganisms from soi samples contaminated with paper and textile industry effluents using agricultural wastes as enrichment medium. Among the 50 isolates, they selected isolate AVS 13 (identified as Bacillus subtilis) a xylano-pectino-cellulolytic microorganism having highest xylanase, pectinase and cellulase activities i.e. 368, 301 and 100 $\mathrm{nkat} / \mathrm{ml}$ respectively. Chen et al. (2011) isolated five strains of bacteria, Pseudomonas sp. M1, Sphingomonas sp., Pseudomonas sp. M2, Achromobacter sp., and Stenotrophomonas sp. from soil which used carboxymethyl cellulose as sole carbon source and reported highest concentration of reducing sugars $(51.36$ $\mathrm{mg}$ ) from carboxymethyl cellulose $(8 \mathrm{~g} / \mathrm{L})$ using Pseudomonas $\mathrm{sp}$. M1. Hong-li et al. (2015) isolated 15 cellulose-degrading bacteria from the mixture of fresh cow dung and fermentation biogas slurry using a culture medium enriched with carboxymethyl cellulose. Two isolates MY6 and FY2 belonging to Stenotrophomonas sp. and Bacillus sp. respectively were selected and showed CMCase activity of $137.36 \mathrm{U} / \mathrm{mL}$ (MY6) and $177.58 \mathrm{U} / \mathrm{mL}$ (FY2) under optimized conditions.

Table 1 Morphological characters and Gram's staining results of microorganisms isolated from soil sample collected from apple pomace dumping site in Himachal Pradesh

\begin{tabular}{|c|c|c|c|c|c|c|}
\hline \multirow[t]{2}{*}{ Isolates } & \multicolumn{5}{|c|}{ Colony Morphology } & \multirow[t]{2}{*}{ Gram's staining results } \\
\hline & Size & Colour & Margin & Elevation & Opacity & \\
\hline APW-01 & large & brown & curled & umbonate & opaque & - \\
\hline APW-02 & medium & brown & entire & raised & opaque & - \\
\hline APW-03 & large & white & entire & raised & opaque & + \\
\hline APW-04 & medium & cream & entire & convex & translucent & - \\
\hline APW-05 & large & white & filiform & flat & opaque & - \\
\hline APW-06 & small & pale-yellow & entire & flat & translucent & + \\
\hline APW-07 & large & light-brown & undulate & umbonate & opaque & - \\
\hline APW-08 & small & ivory & entire & convex & opaque & - \\
\hline APW-09 & small & cream & entire & raised & opaque & - \\
\hline APW-10 & medium & white & entire & umbonate & opaque & + \\
\hline APW-11 & small & white & entire & raised & translucent & - \\
\hline APW-12 & small & white & undulate & raised & opaque & + \\
\hline APW-13 & small & beige & entire & convex & opaque & + \\
\hline APW-14 & small & salmon & entire & convex & opaque & - \\
\hline APW-15 & medium & white & entire & flat & opaque & - \\
\hline
\end{tabular}

Legend: Gram's study; ' + ' = positive, '-' = negative, size; 'small' $=\leq 2 \mathrm{~mm}$, 'medium' $=>2 \leq 5 \mathrm{~mm}$, 'large' $=>5 \mathrm{~mm}$ colony diameter 


\section{Screening of apple pomace utilizing microorganisms}

The enriched cultures were tested for their ability to hydrolyze cellulose (cellulase activity assay), xylan (xylanase activity assay) and produce ethanol, the results of this study are shown in Figure 1. Cellulase activity for all 15 isolates ranged between 228.2 to $502.5 \mathrm{U} / \mathrm{mL} / \mathrm{min}$ and xylanase activity ranged between 185.3 to $1010.7 \mathrm{U} / \mathrm{mL} / \mathrm{min}$. Highest cellulase activity was shown by isolate APW-13 (502.5 U/mL/min), preceded by APW-15 (496 U/mL/min) and APW-12 $(490 \mathrm{U} / \mathrm{mL} / \mathrm{min})$. While highest xylanase activity was exhibited by isolate APW04 (1010.7 U/mL/min) followed by APW-02 (948.7 U/mL/min), APW-15 (905.2 $\mathrm{U} / \mathrm{mL} / \mathrm{min})$ and APW-13 (896.7 U/mL/min). Ethanol on the other hand was significantly produced by only three isolates (APW-2, APW-4 and APW-12). Highest ethanol production $(36 \mathrm{~g} / \mathrm{L})$ was shown by APW-12 and the other two isolates APW-2 and APW-4 produced $21.9 \mathrm{~g} / \mathrm{L}$ and $22.7 \mathrm{~g} / \mathrm{L}$ ethanol respectively. Isolate APW-12 was selected due to its ability to produce ethanol as well as for having higher cellulase and xylanase activities. While, isolate APW-13 was selected for its highest cellulase activity and higher xylanase activity, as consortium cultures along with primary culture Saccharomyces cerevisiae in bioethanol production from waste apple pomace.

Behera et al. (2014) in a similar study on Mangrove soil of Mahanadi river delta, Odisha, India, isolated 15 cellulose degrading bacteria from soil on carboxymethyl cellulose medium. Cellulose degrading ability of each isolate was determined by CMCase activity assay and was found between 2.471 to 98.253 $\mathrm{U} / \mathrm{mL} / \mathrm{min}$ and isolate CDB-12 showed maximum cellulase activity of 98.253 $\mathrm{U} / \mathrm{mL} / \mathrm{min}$. Kaur and Arora (2012) isolated 21 bacterial strains from kitchen waste using nutrient agar medium. These isolates were screened for cellulose degrading potential on mineral salt medium supplemented with carboxymethyl cellulose and out of 21 bacterial isolates, only four exhibited noticeable cellulase activity. Highest cellulase activity $24 \mathrm{U} / \mathrm{mL}$ was observed in isolate CDB-18 Kamble and Jadhav (2012) isolated 25 microorganisms on enrichment medium containing Birchwood xylan as sole carbon source from soil samples collected from coastal areas of Mandovi, Goa, India. These isolates were screened for their xylanolytic potential and identified a bacterial isolate which gave specific xylanase activity of $299.25 \mathrm{U} / \mathrm{mg}$ as a new thermoalkalophilic Bacillus species, similar to Bacillus arseniciselenatis DSM 15340. Arora et al. (2015) isolated 103 thermophilic strains of yeast from soil, out of which 14 isolates produced ethanol using glucose as substrate. However, in this study two yeast isolates (NIRE-K1 and NIRE-K3) fermented both glucose and xylose to ethanol and were identified as strains of Kluyveromyces marxianus.

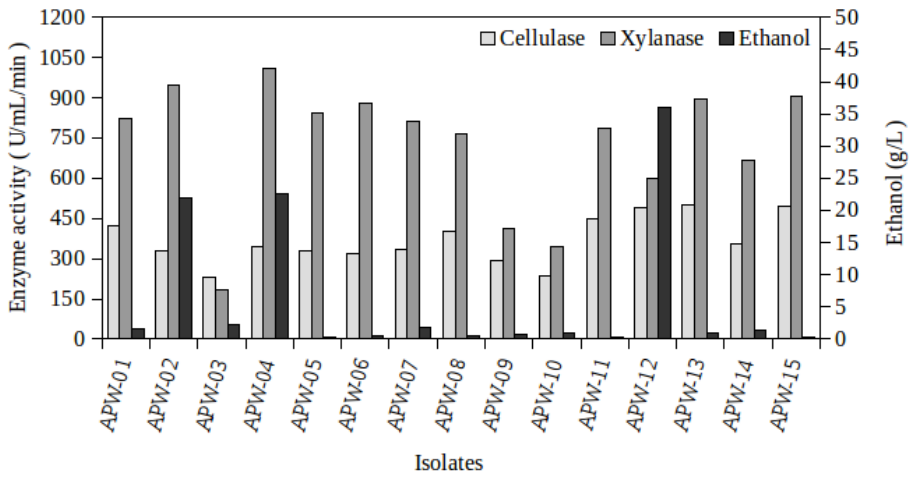

Figure 1 Graph showing cellulase activity, xylanase activity and ethano production by 15 isolates obtained from soil sample of apple pomace dumping site of HPMC, Parwanoo, H.P.

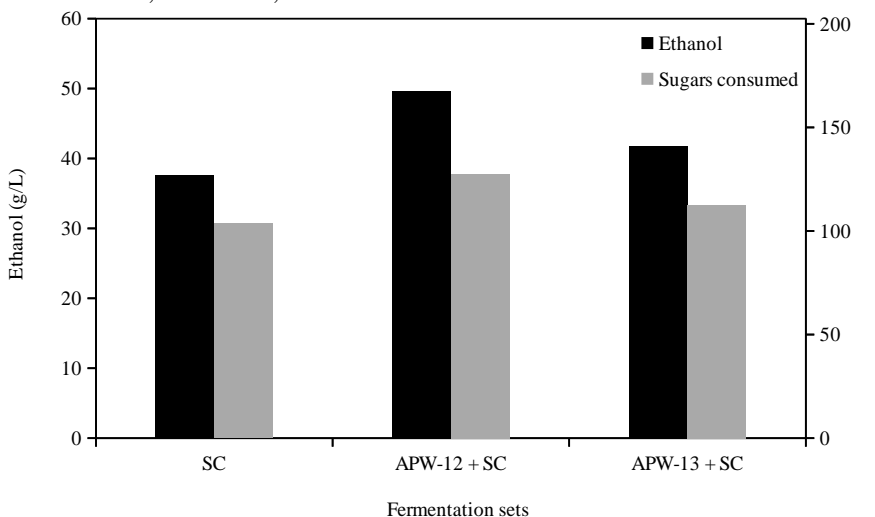

Figure 2Ethanol production from apple pomace using three sets of solid-state fermentations (SSF). Where, first set uses $S$. cerevisiae (SC) only. Second set uses combination of isolate APW-12 and SC and third set uses combination of isolate APW-13 and SC under standard conditions at $30^{\circ} \mathrm{C}$.

\section{Identification of selected isolates}

Isolates APW-12 and APW-13 were further identified on the basis of their morphological and biochemical characteristics (Table 2) and Grams' staining. Based on morphological, Gram's staining and biochemical studies it was found that isolate APW-12 belonged to genus Actinomyces and isolate APW-13 belonged to genus Bacillus. Kim et al. (2012) in a similar study isolated 309 microorganisms on carboxymethylcellulose (CMC) enriched medium from 176 samples collected from various environments like soil, compost and animal waste slurry in Jeju Island, Republic of Korea. They selected three isolates; SL9-9, C516 and S52-2 for their higher cellulolytic activity and broader $\mathrm{pH}$ optimum. Isolates SL9-9 and S52-2 also exhibited xylanase activity of 12.0 and 11.5 Unit/mL respectively and all the three isolates belonged to genus Bacillus. Saroj et al. (2018) isolated 15 thermophilic fungi from soil which were able to grow at $50{ }^{\circ} \mathrm{C}$. These isolates were further screened for their ability to produce cellulase, xylanase and $\beta$-glucosidase. Aspergillus fumigatus JCM 10253 was selected as best isolate for production of extracellular lignocellulolytic enzymes with highes cellulase $(26.2 \mathrm{IU} / \mathrm{mL})$, xylanase $(2.6 \mathrm{IU} / \mathrm{mL})$ and $\beta$-glucosidase $(0.87 \mathrm{IU} / \mathrm{mL})$ activities.

Table 2 Results of biochemical tests performed with selected isolates APW-12 and APW-13 obtained from soil of apple pomace dumping site in Himachal Pradesh

\begin{tabular}{lll} 
Biochemical tests & Results with isolates & \\
\cline { 2 - 3 } & APW-12 & APW-13 \\
\hline Gram's Reaction & Positive & Positive \\
\hline Indole test & Negative & Negative \\
\hline Methyl Red test & Positive & Positive \\
\hline Voges-Proskauer test & Negative & Positive \\
\hline Citrate Utilization test & Negative & Positive \\
\hline Catalase test & Negative & Positive \\
\hline Glucose Utilization & Positive & Positive \\
\hline Sucrose Utilization & Positive & Positive \\
\hline Lactose Utilization & Positive & Negative \\
\hline Mannitol Utilization & Negative & Positive \\
\hline Sorbitol Utilization & Negative & Negative \\
\hline
\end{tabular}

Bioethanol production using selected microorganisms as co-culture with $S$. cerevisiae

Agro-industrial wastes like grape pomace $(9.2 \%$ cellulose, $4 \%$ hemicellulose and $11.6 \%$ lignin), orange peels ( $13.6 \%$ cellulose, $6.1 \%$ hemicellulose and $2.1 \%$ lignin) and banana pseudostem (35.2\% cellulose, $24.4 \%$ hemicellulose and $3.4 \%$ lignin) have been successfully used in bioethanol production (Zheng $\boldsymbol{e t}$ al., 2012, Ververis et al., 2007 and Ingale et al., 2014). Apple pomace used in the present study was composed of $20.8 \%$ cellulose, $23.02 \%$ hemicellulose and $17.7 \%$ lignin. Also, initial amount of reducing sugars present in apple pomace was found to be $4.1 \%(\mathrm{w} / \mathrm{w})$.

Three sets of SSF were performed for bioethanol production using different combination of microorganisms and the results of this study are shown in Figure 2. In the first set, the fermentation was carried using $S$. cerevisiae withou addition of any co-culture. In second and third sets of fermentation, the isolates APW-12 and APW-13 were used as co-culture with $S$. cerevisiae respectively. When used as co-culture with $S$. cerevisiae, APW-12 showed a complementary effect increasing the ethanol production to $49.64 \mathrm{~g} / \mathrm{L}$ from $37.63 \mathrm{~g} / \mathrm{L}$ where $S$. cerevisiae was used individually. Also, isolate APW-13 exhibited additive effect when used as co-culture with $S$. cerevisiae, producing $41.7 \mathrm{~g} / \mathrm{L}$ ethanol. As both APW-12 and $S$. cerevisiae are ethanol producers and it can be clearly seen than $S$. cerevisiae enhanced ethanol production in the presence of APW-13 due to its abilities to produce extracellular cellulases and xylanases.

Benjamin et al. (2014) in a similar study isolated 3 strains of Aspergillus niger from soil and used them as co-cultures with $S$. cerevisiae for bioethanol production from dried banana peel waste. $2.75 \%$ ethanol was produced during simultaneous saccharification and fermentation carried out with $5 \%$ banana pee powder using $4 \%$ A. niger strain B along with $3 \%$ S. cerevisiae at $30{ }^{\circ} \mathrm{C}$ at $\mathrm{pH}$ 6.0 for $72 \mathrm{~h}$. Swain et al. (2013) produced $172 \mathrm{~g} / \mathrm{kg}$ ethanol from dried sweet potato using Trichoderma sp. and $S$. cerevisiae. This study used solid-state fermentation with $50 \mathrm{~g}$ substrate at $\mathrm{pH} 5.0$, temperature $30{ }^{\circ} \mathrm{C}$, inoculum size 10\% (1:4 Trichoderma sp. : S. cerevisiae), moisture content $80 \%$, nitrogen source (ammonium sulphate $0.2 \%$ ) and at incubation time of $72 \mathrm{~h}$. Waghmare $\boldsymbol{e t}$ al. 2018 biologically pretreated sorghum husk using Phanerochaete chrysosporium MTCC 4955 resulting in $103.0 \mathrm{mg} / \mathrm{g}$ reducing sugars in the hydrolysate. Ethanol 
production from the hydrolysate using Saccharomyces cerevisiae KCTC 7296 Pachysolen tannophilus MTCC 1077 individually and as co-cultures in $48 \mathrm{~h}$ fermentation resulted in ethanol yields of $2.113,1.095$, and $2.348 \%$ respectively. Yeunyaw and Yuwa-amornpitak (2018) used amylolytic fungus Amylomyce rouxii YTH3 as co-culture with Saccharomyces cerevisiae TISTR 5088 in single step ethanol production from cassava starch and reported $73.68 \mathrm{~g} / \mathrm{L}$ of ethanol from $20 \%$ cassava starch medium containing $115.94 \mathrm{~g} / \mathrm{L}$ fermentable sugars in 96 h fermentation.

\section{CONCLUSION}

Out of 15 microorganisms isolated from apple pomace waste soil, only two isolates (APW-12 and APW-13) capable of utilizing apple pomace as sole nutrient source were selected to co-culture with $S$. cerevisiae for bioethano production on dried apple pomace as substrate in solid-state fermentation. Coculturing $S$. cerevisiae with APW-12 and APW-13 exhibited an increase in ethanol production by $8 \%$ and $4 \%$ respectively. Isolate APW-12 is found to be a suitable microorganism for its use as co-culture in ethanolic fermentation with $S$. cerevisiae and can also be used individually in a combined bioprocess for ethanol production. On the other hand, APW-13 exhibited cellulase and xylanase activity required for enzymatic hydrolysis of lignocellulosic biomass to increase the available sugars for fermentation.

\section{REFERENCES}

Aneja, K. R. (2003). Biochemical activities of microorganisms. In Experiments in Microbiology, Plant Pathology and Biotechnology (4th ed., pp. 245-275). New Delhi: New Age International.

Arora, R., Behera, S., Sharma, N. K., \& Kumar, S. (2015). A new search for thermotolerant yeasts, its characterization and optimization using response surface methodology for ethanol production. Frontiers in Microbiology, 6, 889 https://doi.org/10.3389/fmicb.2015.00889

Behera, B. C., Parida, S., Dutta, S. K., \& Thatoi, H. N. (2014). Isolation and identification of cellulose degrading bacteria from Mangrove soil of Mahanadi River Delta and their cellulase production ability. American Journal of Microbiological Research, 2(1), 41-46. https://doi.org/10.12691/ajmr-2-1-6 Benjamin, C., Singh, P. K., \& Dipuraj, P. S. (2014). Bio-ethanol production from banana peel by simultaneous saccharification and fermentation process using cocultures Aspergillus niger and Saccharomyces cerevisiae. International Journal of Current Microbiology and Applied Sciences,3(5), 84-96.

Berezina, O. V., Brandt, A., Yarotsky, S., Schwarz, W. H., \& Zverlov, V. V. (2009). Isolation of a new butanol-producing Clostridium strain: high level of hemicellulosic activity and structure of solventogenesis genes of a new Clostridium saccharobutylicum isolate. Systematic and Applied Microbiology, 32(7), 449-459. https://doi.org/10.1016/j.syapm.2009.07.005

Bhushan, S., Kalia, K., Sharma, M., Singh, B., \& Ahuja, P. S. (2008). Processing of apple pomace for bioactive molecules. Critical Reviews in Biotechnology, 28(4), 285-296.https://doi.org/10.1080/07388550802368895

Chatanta, D. K., Attri, C., Gopal, K., Devi, M., Gupta, G., \& Bhalla, T. C (2007). Bioethanol production from apple pomace left after juice extraction. The Internet Journal of Microbiology, 5(2), 1-5.https://doi.org/10.5580/3a8

Chen, H. J., Chang, H. J., Fan, C., Chen, W. H., \& Lee, M. S. (2011). Screening, isolation and characterization of cellulose biotransformation bacteria from specific soils. International Conference on Environment and Industrial Innovation, 12, 216-220.

Choudhary, J., Singh, S., \& Nain, L. (2016). Thermotolerant fermenting yeasts for simultaneous saccharification fermentation of lignocellulosic biomass Electronic Journal of Biotechnology, 21, 82-92. https://doi.org/10.1016/j.ejbt.2016.02.007

Gama, R., Van Dyk, J. S., \& Pletschke, B. I. (2015). Optimisation of enzymatic hydrolysis of apple pomace for production of biofuel and biorefinery chemicals using commercial enzymes. 3 Biotech, 5(6), 1075-1087. https://doi.org/10.1007/s13205-015-0312-7

Hahn-Hägerdal, B., Galbe, M., Gorwa-Grauslund, M. F., Lidén, G., \& Zacchi, G. (2006). Bio-ethanol - the fuel of tomorrow from the residues of today. Trends in Biotechnology, 24(12), 549-556. https://doi.org/10.1016/j.tibtech.2006.10.004 Hong-li, Z., Xiao, Y., Dong-mei, X., Lu, Z., Kai-zhong, T., Xing-yao, X., et al. (2015). Isolation, identification and characterization of cellulose-degradation bacteria from fresh cow dung and fermentation biogas slurry. Research \& Reviews: Journal of Microbiology and Biotechnology, 4(3), 30-37.

Ingale, S., Joshi, S. J., \& Gupte, A. (2014). Production of bioethanol using agricultural waste: banana pseudo stem. Brazilian Journal of Microbiology, 45(3), 885-892. https://doi.org/10.1590/S1517-83822014000300018

Joshi, V. K., \& Attri, D. (2006). Solid state fermentation of apple pomace for the production of value added products. Natural Product Radiance, 5(4), 289-296.

Jouzani, G. S., \& Taherzadeh, M. J. (2015). Advances in consolidated bioprocessing systems for bioethanol and butanol production from biomass: a comprehensive review. Biofuel Research Journal, 5(1), 152-195.

Kamble, R. D., \& Jadhav, A. R. (2012). Isolation, purification, and characterization of xylanase produced by a new species of Bacillus in solid state fermentation. International Journal of Microbiology 2012.https://doi.org/10.1155/2012/683193

Kang, Q., Appels, L., Tan, T., \& Dewil, R. (2014). Bioethanol from lignocellulosic biomass: current findings determine research priorities. The Scientific World Journal, 2014. https://doi.org/10.1155/2014/298153

Kaur, M., \& Arora, S. (2012). Isolation and screening of cellulose degrading bacteria in kitchen waste and detecting their degrading potential. IOSR Journal of Mechanical and Civil Engineering, 1(2), 33-35.

Kim, Y. K., Lee, S. C., Cho, Y. Y., Oh, H. J., \& Ko, Y. H. (2012). Isolation of cellulolytic Bacillus subtilis strains from agricultural environments. ISRN Microbiology, 2012. https://doi.org/10.5402/2012/650563

Kumar, D., Verma, R., \& Bhalla, T. C. (2010). Citric acid production by Aspergillus niger van. Tieghem MTCC 281 using waste apple pomace as a substrate. Journal of Food Science and Technology, 47(4), 458-460. https://doi.org/10.1007/s13197-010-0077-2

Kumar, P., Barrett, D. M., Delwiche, M. J., \& Stroeve, P. (2009). Methods for pretreatment of lignocellulosic biomass for efficient hydrolysis and biofuel production. Industrial \& Engineering Chemistry Research, 48(8), 3713 3729.https://doi.org/10.1021/ie801542g

Pathania, S., Sharma, N., \& Handa, S. (2018). Utilization of horticultural waste (apple pomace) for multiple carbohydrase production from Rhizopus delemar F2 under solid state fermentation. Journal of Genetic Engineering and Biotechnology, 16(1), 181-189. https://doi.org/10.1016/j.jgeb.2017.10.013

Saroj, P., Manasa, P., \& Narasimhulu, K. (2018). Characterization of thermophilic fungi producing extracellular lignocellulolytic enzymes for lignocellulosic hydrolysis under solid-state fermentation. Bioresources and Bioprocessing, 5(1).https://doi.org/10.1186/s40643-018-0216-6

Scully, S., \& Orlygsson, J. (2014). Recent advances in second generation ethanol production by thermophilic bacteria. Energies, 8(1), 1-30 https://doi.org/10.3390/en8010001

Singh, A., Kaur, A., Dua, A., \& Mahajan, R. (2015). An efficient and improved methodology for the screening of industrially valuable xylano-pectinocellulolytic microbes. Enzyme Research, 2015. https://doi.org/10.1155/2015/725281

Swain, M. R., Mishra, J., \& Thatoi, H. (2013). Bioethanol production from sweet potato (Ipomoea batatas L.) flour using co-culture of Trichoderma sp. and Saccharomyces cerevisiae in solid-state fermentation. Brazilian Archives of Biology and Technology, 56(2), 171-179.

Ververis, C., Georghiou, K., Danielidis, D., Hatzinikolaou, D. G., Santas, P., Santas, R., et al. (2007). Cellulose, hemicelluloses, lignin and ash content of some organic materials and their suitability for use as paper pulp supplements. $\begin{array}{llll}\text { Bioresource } & \text { Technology, 296-301. }\end{array}$ https://doi.org/10.1016/j.biortech.2006.01.007

Wackett, L. P. (2008). Microbial-based motor fuels: science and technology. Microbial Biotechnology, 1(3), 211-225. https://doi.org/10.1111/j.1751 7915.2007.00020.x

Waghmare, P. R., Khandare, R. V., Jeon, B. H., \& Govindwar, S. P. (2018) Enzymatic hydrolysis of biologically pretreated sorghum husk for bioethanol production. Biofuel Research Journal, 5(3), 846-853 https://doi.org/10.18331/BRJ2018.5.3.4

Yeunyaw, P., \& Yuwa-amornpitak, T. (2018). Bioconversion of cassava starch to bio-ethanol in a single step by co-cultures of Amylomyces rouxii and Saccharomyces cerevisiae. Songklanakarin Journal of Science and Technology, 40(4), 776-783

Zheng, Y., Lee, C., Yu, C., Cheng, Y. S., Simmons, C. W., Zhang, R., et al. (2012). Ensilage and bioconversion of grape pomace into fuel ethanol. Journal of Agricultural and Food Chemistry, 60(44), 11128-11134 https://doi.org/10.1021/jf303509v 